\title{
Thalamotomy for Essential Tremor: A Very Long-Term Follow-Up
}

\author{
Ulrika Sandvik*,a $^{*}$ Åsa Rosendal ${ }^{\mathrm{b}}$, Jan van Doorn $^{\mathrm{b}}$, Richard Birgander ${ }^{\mathrm{c}}$ and Patric Blomstedt ${ }^{\mathrm{a}}$ \\ ${ }^{a}$ Departments of Pharmacology and Clinical Neuroscience, Division of Neurosurgery, University Hospital of Umeå, \\ Sweden \\ ${ }^{b}$ Departments of Clinical Sciences, Division of Speech and Language Pathology, Umeå University, Sweden \\ ${ }^{c}$ Departments of Radiology, Division of Neuroradiology, University Hospital of Umeå, Sweden
}

\begin{abstract}
Background: DBS (deep brain stimulation) is currently the golden standard in the surgical treatment of ET (essential tremor). Despite the benefits of DBS, there remain situations where lesional surgery may provide an alternative.

Objective: To perform a very long-term retrospective evaluation of thalamotomies for ET.

Methods: Nine patients who underwent thalamotomy for ET during 1972-1999 (follow-up period 20.8 \pm 5.2 years) were assessed with regard to tremor scores, side effects, and quality of life, as well as lesion size and location.

Results: All patients had tremor recurrence, although handfunction remained slightly better on the treated side than on the non-treated side. Side effects that could be attributed to the procedure were frequent and did in some cases result in a disability for the patient. Quality of life was poorer in this group than in an age-adjusted healthy population. No correlation between lesion size, location, and long-term outcome could be established.

Conclusions: In this study population the benefits of thalamotomies were limited, while complications were frequent.
\end{abstract}

Keywords: Essential tremor, thalamotomy, vim.

\section{INTRODUCTION}

Lesional procedures in the thalamus (thalamotomies) were introduced in 1954 by Hassler in the treatment of Parkinsonian tremor and were later also used for ET [1]. After the introduction of Deep Brain Stimulation (DBS) by Benabid in 1987, this technique has gradually replaced lesional surgery and DBS is at present the treatment of choice for ET [2]. DBS is considered to be a reversible technique with fewer risks, especially in bilateral procedures [3]. Disadvantages of DBS includehardware related complications, the high cost of the procedure, and the more cumbersome life-long follow-up [4]. The American Academy of Neurology gives thalamotomy evidence class $\mathrm{C}$ (probably effective) in a recent guideline update [5].For these reasons lesional surgery has recently been discussed as an alternative to DBS in certain selected cases [4].We have therefore decided to review the long-term results of thalamotomies performed at our department by scoring the present symptoms and describing the presence of persistent neurological deficits which might be attributed to the procedure.

\section{PATIENTS AND METHODS}

The study reviews patients with ET previously operated upon with lesions in the ventrolateral thalamus. Participation was offered to patients operated upon during 1972-1999 at the Department of Neurosurgery, University Hospital of Umeå. The study was approved by the local ethical board

*Address correspondence to this author at the Dept. of Neurosurgery, University Hospital of Umeå, SE-90185 Umeå, Sweden; Tel: +4690 7850000; Fax: +46 901380 45; E-mail: ulrika.sandvik@neuro.umu.se and informed consent was obtained from the patients. The patients were identified from operation records and those under the age of 80 and not suffering from other neurological disorders were offered participation in the study. During this period 107 thalamotomies were performed on93 patients. Of these 93 patients, 39 were deceased, 39 were over 80 years of age, 4 had moved to a different administrative region, and 2 were excluded due to recent stroke. Nine suitable patients (5 females) (operated upon during 1981-1996)were thus identified and included in the study. The follow-up was conducted $20.8 \pm 5.2$ years after the operation, when the patients had reached a mean age of $69.3 \pm 10.7$ years.Patient characteristicsare presented in Table $\mathbf{1}$.

\section{Surgery}

A stereotactic CT scan using the Laitinen stereoadapter was done in all patients, and an additional ventriculography in three patients [6]. The operation was performed with the Laitinen stereotactic frame [7]. Lesions were performed at on average $2.1 \pm 1.1$ locations at $65-75^{\circ} \mathrm{C}$ during $10-70 \mathrm{~s}$, modulated according to the tremor response. In one case (pat. 2) an ipsilateral re-thalamotomy was performed one year after the initial operation. One patient (pat. 9) underwent staged bilateral thalamotomies. The surgical details are presented in Table 2.

\section{Evaluation \\ Clinical and Subjective}

The patients in the study were offered an appointment at the outpatient clinic. During the consultation the patients were subjected to a full neurological assessment including 
Table 1. Descriptives

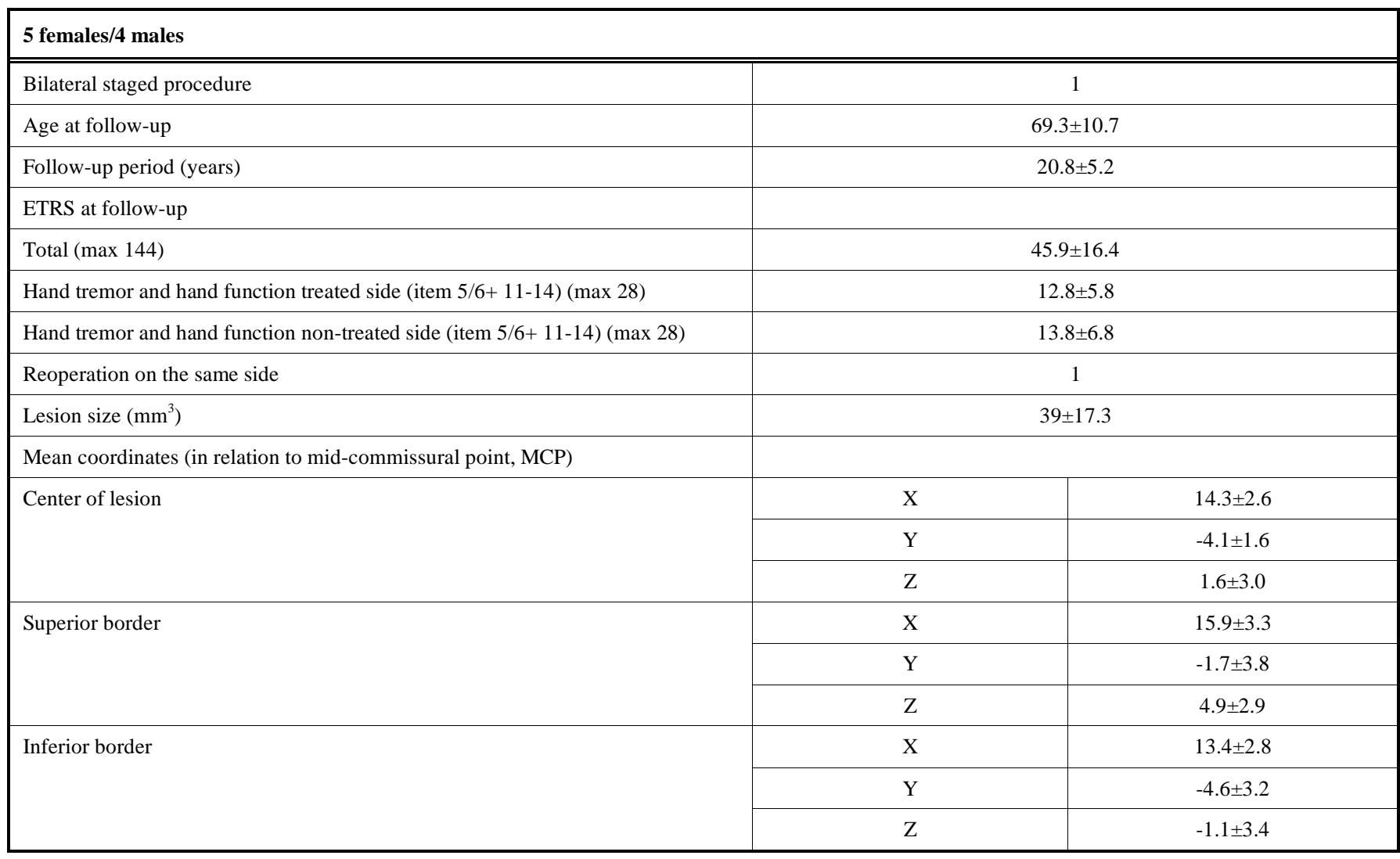

Table 2. Details Extracted from Operation Reports

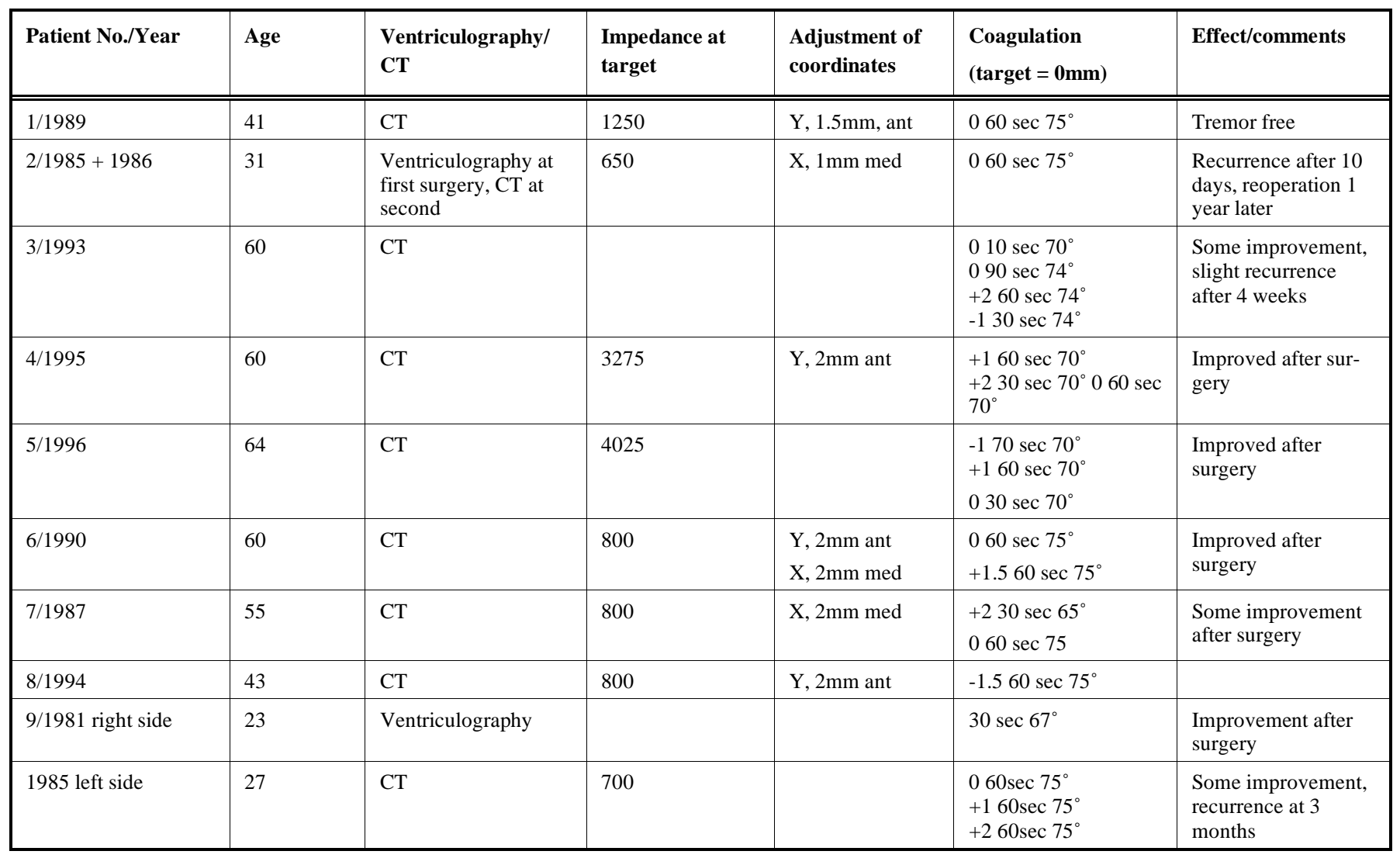


Table 3. Follow-Up Characteristics

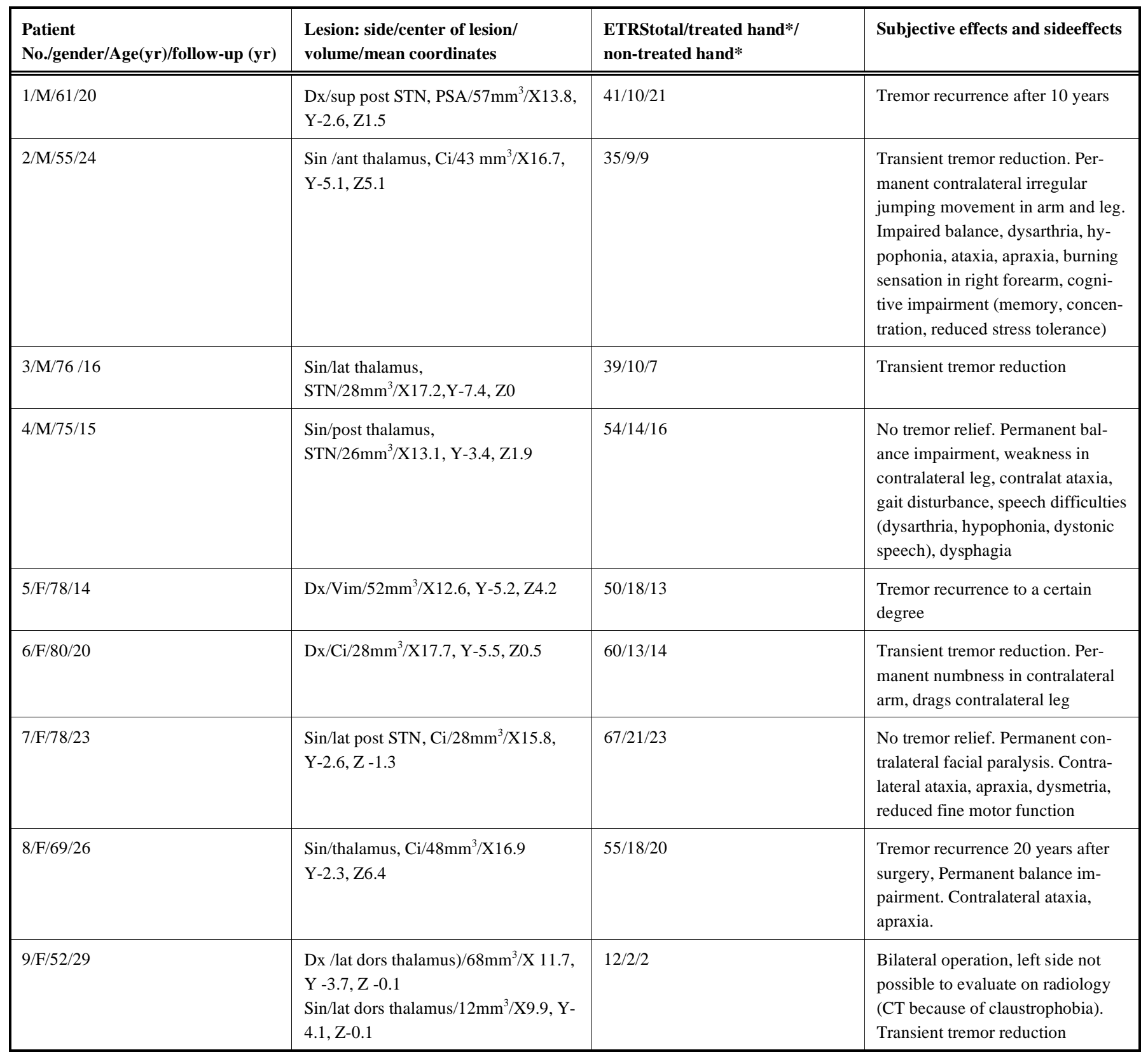

Abbreviations: STN, subthalamic nucleus; PSA, posterior subthalamic area; $\mathrm{Ci}$, internal capsule; Vim, ventrolateral thalamus.

* item 5/6 and 11-14.

tremor evaluation using the Essential Tremor Rating Scale (ETRS) [8]. Patients were also actively interrogated in a standardized fashion regarding side effects that could be attributed to thalamotomies. The following tests were also performed: Balance was assessed using Berg's Balance Score (BBS); [9, 10] Speech was recorded and analyzed regarding dysarthria, dysphonia, and voice tremor by a panel of five speech-language pathologists. The material consisted of recorded voice samples reading a standard text, 1-6 seconds sustained phonation $(/ \mathrm{a} /, / \mathrm{i} /$ and / $\mathrm{u} /$ ) and the patients' self-assessments. Verbal fluency was evaluated using a standardized test [11]. Quality of life was examined with SF-36 and Quality of Life in Essential Tremor (QUEST) [12, 13]. QUEST data were computed into a Summary Index (QUEST-SI) [13]. Lesion size and location were analyzed using MRI studies, while coordinates were calculated on the Frame link planning station ${ }^{\circledR}$ (Medtronic, Minneapolis, USA). When possible, calculations were performed on a 3 Tesla MR (Philips Intera, The Netherlands) using a T1 weighted volume examination with $1-\mathrm{mm}$ slices and a T2 weighted transaxial examination with $2-\mathrm{mm}$ slices. However, in one patient (pat. 9), a stereotactic CT with 1-mm slices was performed because of claustrophobia.The volume of the lesions was calculated using the formula $4 / 3 \pi r^{a} r^{b} r^{c}$ (a, b and $\mathrm{c}$ representing the different radii of the lesion).

\section{Statistics}

The results are expressed as the mean \pm standard deviation and range. Correlation between lesion size and tremor scores was examined using Spearman's correlation. 


\section{RESULTS}

Effects and side effects found in this population are presented in Table $\mathbf{3}$ and are further described below.

\section{Tremor}

During the interview all but two patients reported tremor reduction after the operation; however, none of the patients considered that they currently experienced any lasting effect. The longest tremor-free span was reported to be 20 years. When evaluated with the ETRS, the total score was $45.9 \pm 6.4$ (range 12-67). Hand tremor (Item 5/6) and hand function (Items 11-14) scored 12.8 \pm 5.8 (range 2-21) on the treated side and 13.8 \pm 6.8 (range 2-23) on the non-treated side.

\section{Side Effects}

During the interview three patients reported that they regretted undergoing the procedure (pats. 2, 4, and 7) due to the severe side effects. Patient 2 reported (with our terminology) permanent contralateral irregular jumping movements in the right arm and leg, ataxia, apraxia, impaired balance, a burning sensation in the right forearm, dysarthria, hypophonia, cognitive impairment, and reduced stress tolerance. Similar symptoms were reported by patients 4 and 7 and, to a lesser extent, patients 6 and 8. Most of the reported motor symptoms were supported by the findings during the clinical examination.

Bergs balance test showed a mean score of $41.7 \pm 13.5$ (range 21-56), which is between acceptable and good balance. The item "tandem standing" was generally the most impaired. When locomotion was tested during the neurological examination eight patients exhibited abnormal tandem walking [14].

Speech samples could be analyzed in 8 of the patients. Six of them were found to have speech problems in the form of abnormal voice quality (5 patients), voice perturbations (4), voice tremor (3), elevated tone of voice (3), abnormal articulation (3), and abnormal speech rate (2). The speech symptoms for one patient were sufficiently severe to be considered dysarthria, consistent with the patient's self report.

Verbal fluency showed a large variation in age-adjusted results. While the results were in conformity with the normal population on the two simpler tasks, the patients performed worse on the two more complicated parts, especially Part S (generating as many five-lettered animals as possible beginning with the letter S), where they achieved only $27.8 \%$ of the expected result.

Quality of life according to SF-36 was lower compared to a healthy Swedish population (Fig. 1) [15]. The overall QUEST-SI was 28.5 \pm 12.7 , where ADL and psychosocial subscales were the most impaired.

Lesion size and location are given for each patient in Table 3. The mean size of the lesions was $39.0 \pm 17.3 \mathrm{~mm}^{3}$ (range 12-68). A regression analysis of lesion size and ETRS for hand function and hand tremor (Items 5-6 and 1114) for the treated hand did not render any significant results. The mean coordinates of the centre of the lesion in relation to the mid-commissural point were $X=14.3 \pm 2.6$ (range 9.917.7), $\mathrm{Y}=-4.1 \pm 1.6$ (range $-7.4--2.3$ ) and $\mathrm{Z}=1.6 \pm 3.0$ (range 1.3-6.4.) The lesions were located $i$ various parts of the thalamus, internal capsule (CI), subthalamic nucleus (STN) and the posterior subthalamic area (PSA).

\section{DISCUSSION}

\section{Tremor}

In this series none of the patients considered that they had any positive remaining effect of the procedure at the evaluation. Some patients denied any effect at all, while the patient with the longest lasting effect reported a tremor-free period of 20 years. The ETRS scores at evaluation were high, at about the level usually seen in patients during preoperative assessment before DBS [16]. The treated side did, however, still have a slightly lower score regarding hand tremor and hand function (Items 5/6 and 11-14) compared to the non-treated side. This might suggest some lasting effect since it may be assumed that the patients at baseline had a more severe tremor in the treated hand. In the literature, beneficial results have also been reported in long-term evaluations [17-27]. In some patients the tremor has not been shown to recur during the follow-up time[22].

\section{Side Effects}

The severity and number of the side effects that the patients themselves believed to be caused by the operation were distressingly high. Even though it is difficult to be certain due to the long time which has passed since the operation, it seems natural to assume that most of these side effects were caused by the operation since they are in accord with previously reported side effects of thalamotomy. In a recent paper Schuurman et al., describe neurological side effects of surgery being more frequent after thalamotomy [28].

The rate of persistent severe complications has been reported to range from $9 \%$ to $28 \%[19,20]$. The most frequently described side effects included cerebellar complications such as speech difficulties (dysarthria, dysphasia, hypophonia), dysequlibrium, apraxia, ataxia, and gait disturbances, as well as contralateral weakness, most probably due to affection of the internal capsule $[3,19,21-24,26,27,29$ $33]$. Facial numbness and weakness as well as cognitive impairment have also been described [19, 20, 27, 34].

Balance is difficult to evaluate in these patients because impaired balance control is typical in ET, even in the early stages [32]. These deficits might be due to the cerebellar impairment in ET. Tandem movement is most often affected in ET, whereas normal gait suffers little impairment [14, 35]. Abnormal tandem walking, which is considered to be more than three missteps per minute, was seen in eight out of nine patients and should probably be interpreted as a manifestation of the disease rather than a side effect of the operation. When assessed by the BBS the group exhibited a good to acceptable balance. Three patients reported impaired balance after surgery, which, however, could not be verified in the neurological examination.

Speech impairment was observed in several of the patients. The analysis performed by speech-language pathologists could not determine any consistent pattern of pathology in the group, but the affected speech features were components associated with dysphonic voice and dysarthric speech. Thalamotomy has been reported to cause hypophonia, and 


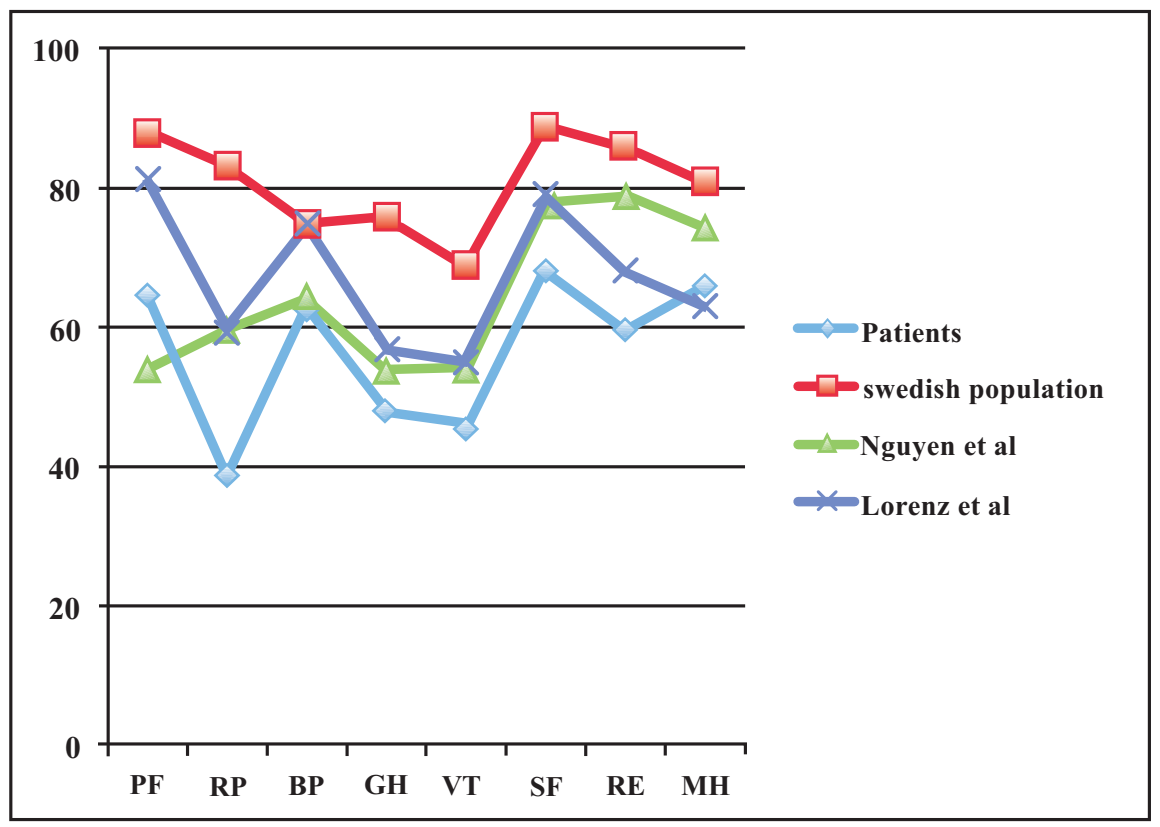

Fig. (1). SF-36 subscores. Comparison of SF-36 health profiles for patients in this study to healthy Swedish population [15] and the profiles for ET patients from the Nguyen et al., study (32 patients) as well as the Lorenz et al., study (102 patients) [46, 47].

Abbreviations: $\mathrm{PF}=$ physical functioning, $\mathrm{RP}=$ role physical, $\mathrm{BP}=$ bodily pain, $\mathrm{GH}=$ general health, $\mathrm{VT}=\mathrm{vitality}, \mathrm{SF}=$ social functioning, $\mathrm{RE}=$ role-emotional, $\mathrm{MH}=$ mental health.

dysarthria is frequently reported [19, 31]. Dysarthria might be caused either by an affection of the cerebellothalamic fibresor by involvement of the internal capsule [36-41]. Even though the speech analysis demonstrated varying forms of speech abnormalities in most of our patients, only one was considered to have a dysarthria. This is in contrast to our clinical opinion and the reports from the patients. This difference is probably caused, however, by a difference in terminology.

Verbal fluency was reduced in this series as compared to an age-matched normal population, especially concerning the most difficult task, where the patients achieved only $27.8 \%$ of what was expected. This is in accord with the literature, where dysphasia has been reported in up to $42 \%$ of thalamotomies in the dominant hemisphere [42,43]. In a more recent series Schuurman et al. have shown the decline in verbal fluency to be equal after both left- sided thalamotomy and DBS [44].

Quality of life was reduced in all patient compared to an age-matched healthy population. This is, however, known to be the case also in ET patients who have not undergone surgery, especially in aspects related to psychosocial functioning [45]. Since only a few SF-36 profile shave been done on an ET population, it is difficult to speculate on what might be caused by the disease itself and what might be caused by side effects of the surgical procedure. Our patients had a more poor quality of life than the non-operated patients presented by Nguyen et al., and Lorenz et al., [46, 47] (Fig. 1). Their series did, however, consist of newly diagnosed patients and patients with probable ET. The QUEST-SI score was slightly higher, indicating slightly better quality of life, than in the literature in general [48]. The significance of this is difficult to evaluate, however, due to the small number of publications using QUEST.

\section{Radiology: Location of Lesion and Lesion Size}

No correlation between lesion size and ETRS at followup could be seen in our series. The lesions showed a wider distribution in both the thalamic and subthalamic area than might have been expected from the coordinates used during surgery. No correlation between location and tremor relief was seen. Regarding side effects, the lesions seemed to involve the internal capsule in four patients, and all these patients exhibited contralateral motor side effects.

Attempts to relate effects and side effects to the size and localization of the lesion have been few in number. Some studies suggest no correlation between lesion size, location within the ventrolateral thalamus, and tremor reduction, but show the larger lesions to be associated with more complications $[49,50]$. Other studies suggest the effective lesion to be approximately $40-70 \mathrm{~mm}^{3}[21,26,51]$. The lesions seem to have varied considerably in size between different surgeons.

\section{Limitations}

There are several limitations in this retrospective study. The most obvious problem is the lack of preoperative grading, such as ETRS, of tremor. However, to the best of our knowledge, there are no studies on thalamotomies where a preoperative ETRS has been used. It is important to notice that the evaluation of the effect of thalamotomies in this paper are based on the patients' subjective experience many years after surgery, and can hence never be considered to be equally reliable as a pre- and postoperative ETRS scoring. Regarding some of the symptoms, it is also difficult to know if they are a complication of the procedure or if they might be caused by the progress of the disease, or simply by natural aging. The small number of subjects studied in this paper is also a limitation. 
We can conclude, however, that thalamotomy did in this small series result in a temporary relief of tremor in some patients, ranging up to 20 years. Even if it seems likely that some effect was retained even at the evaluation, the patients did present a tremor level similar to patients considered for DBS. The severity and number of the side effects that the patients themselves believed to be caused by the operation were distressingly high, and most of these side effects are likely to have been caused by the operation. In some cases, it is possible that a more accurately placed lesion might have improved the effect and diminished the side effects. It is therefore possible that, in the future, the ongoing technical development might make thalamotomies an alternative to DBS. However, in this study of the very long-term effects of thalamotomies, the disadvantages clearly outweighed the benefits.

\section{CONFLICT OF INTEREST}

The authors report no conflict of interest.

\section{ACKNOWLEDGMENTS}

We acknowledge our debt of gratitude to Research Engineer Anders Asplund, Physiotherapist Laura Eyvindson, DBS Nurses Anna Fredricks and Gull-Brith Widefjäll.

This work was supported by grants from the Neurological Foundation at Umeå University.

\section{REFERENCES}

[1] Hassler R, Riechert T. Indikationen und Lokalisationsmethoden der gezielten Hirnoperationen. Nervenarzt 1954; 25(11): 441-7.

[2] Benabid AL, Pollak P, Louveau A, Henry S, de Rougemont J. Combined (thalamotomy and stimulation) stereotactic surgery of the VIM thalamic nucleus for bilateral Parkinson disease. Appl Neurophysiol 1987; 50(1-6): 344-6.

[3] Blomstedt P, Hariz MI. Are complications less common in deep brain stimulation than in ablative procedures for movement disorders? Stereotact Funct Neurosurg 2006; 84(2-3): 72-81.

[4] Hooper AK, Okun MS, Foote KD, et al. Clinical cases where lesion therapy was chosen over deep brain stimulation. Stereotact Funct Neurosurg 2008; 86(3): 147-52.

[5] Zesiewicz TA, Elble RJ, Louis ED, et al. Evidence-based guideline update: treatment of essential tremor: report of the Quality Standards subcommittee of the American Academy of Neurology. Neurology 2011; 77(19): 1752-5.

[6] Laitinen L, Liliequist B, Fagerlund M, Eriksson T. An adapter for computed tomography-guided stereotaxis. Surg Neurol 1985; 23: 559-66.

[7] Laitinen LV. My 50 years of interest in stereotactic and functional neurosurgery. Stereotact Funct Neurosurg 2001; 77(1-4): 7-10.

[8] Fahn S, Tolosa E. Clinical rating scale for tremor. In: Jankovic J, Tolosa E, editors. Parkinson's disease and movement disorders. Munich: Urban and Schwarzenberg; 1993. p. 271-80.

[9] Berg K, Wood-Dauphinee S, Williams JI. The Balance Scale: reliability assessment with elderly residents and patients with an acute stroke. Scand J Rehabil Med 1995; 27(1): 27-36.

[10] Berg KO, Wood-Dauphinee SL, Williams JI, Maki B. Measuring balance in the elderly: validation of an instrument. Can J Public Health 1992; 83 (Suppl 2): S7-11.

[11] Lezak M. Neuropsychological Assessment. 3rd ed. New York: Oxford University Press; 1995.

[12] Ware JE Jr., Sherbourne CD. The MOS 36-item short-form health survey (SF-36). I. Conceptual framework and item selection. Med Care 1992; 30(6): 473-83.

[13] Troster AI, Pahwa R, Fields JA, Tanner CM, Lyons KE. Quality of life in Essential Tremor Questionnaire (QUEST): development and initial validation. Parkinsonism Relat Disord 2005; 11(6): 367-73.

[14] Stolze H, Petersen G, Raethjen J, Wenzelburger R, Deuschl G. The gait disorder of advanced essential tremor. Brain 2001; 124(Pt 11): 2278-86.
[15] Sullivan MK, Taft J Vc, Ware JE. SF-36 Hälsoenkät. Svensk manual och tolkningsguide, 2:a upplagan (Swedish Manual and Interpretation Guide, 2nd Edition). 2nd ed. Gothenburg: Sahlgrenska University Hospital; 2002.

[16] Blomstedt P, Sandvik U, Tisch S. Deep brain stimulation in the posterior subthalamic area in the treatment of essential tremor. Mov Disord 2010; 25(10): 1350-6.

[17] Laitinen L. Stereotaxic treatment of hereditary tremor. Acta Neurol Scand 1965; 41: 74-9.

[18] Jankovic J, Cardoso F, Grossman RG, Hamilton WJ. Outcome after stereotactic thalamotomy for parkinsonian, essential, and other types of tremor. Neurosurgery 1995; 37(4): 680-6.

[19] Zirh A, Reich SG, Dougherty PM, Lenz FA. Stereotactic thalamotomy in the treatment of essential tremor of the upper extremity: reassessment including a blinded measure of outcome. J Neurol Neurosurg Psychiatry 1999; 66(6): 772-5.

[20] Schuurman PR, Bosch DA, Bossuyt PM, et al. A comparison of continuous thalamic stimulation and thalamotomy for suppression of severe tremor. N Engl J Med 2000; 342(7): 461-8.

[21] Nagaseki Y, Shibazaki T, Hirai T, et al. Long-term follow-up results of selective VIM-thalamotomy. J Neurosurg 1986; 65(3): 296-302.

[22] Shahzadi S, Tasker RR, Lozano A. Thalamotomy for essential and cerebellar tremor. Stereotact Funct Neurosurg 1995; 65(1-4): 11-7.

[23] Goldman MS, Ahlskog JE, Kelly PJ. The symptomatic and functional outcome of stereotactic thalamotomy for medically intractable essential tremor. J Neurosurg 1992; 76(6): 924-8.

[24] Tasker RR. Deep brain stimulation is preferable to thalamotomy for tremor suppression. Surg Neurol 1998; 49(2): 145-53.

[25] Cooper IS. Heredofamilial tremor abolition by chemothalamectomy. Arch Neurol 1962; 7: 129-31.

[26] Ohye C, Hirai T, Miyazaki M, Shibazaki T, Nakajima H. Vim thalamotomy for the treatment of various kinds of tremor. Appl Neurophysiol 1982; 45(3): 275-80.

[27] Mohadjer M, Goerke H, Milios E, Etou A, Mundinger F. Longterm results of stereotaxy in the treatment of essential tremor. Stereotact Funct Neurosurg 1990; 54-55: 125-9.

[28] Schuurman PR, Bosch DA, Merkus MP, Speelman JD. Long-term follow-up of thalamic stimulation versus thalamotomy for tremor suppression. Mov Disord 2008; 23(8): 1146-53.

[29] Tasker RR, Siqueira J, Hawrylyshyn P, Organ LW. What happened to VIM thalamotomy for Parkinson's disease? Appl Neurophysiol 1983; 46(1-4): 68-83.

[30] Yasui N, Narabayashi H, Kondo T, Ohye C. Slight cerebellar signs in stereotactic thalamotomy and subthalamotomy for parkinsonism. Appl Neurophysiol 1976; 39(3-4): 315-20.

[31] Jankovic J, Cardoso F, Grossman RG, Hamilton WJ. Outcome after stereotactic thalamotomy for parkinsonian, essential, and other types of tremor. Neurosurgery 1995; 37(4): 680-6.

[32] Kronenbuerger M, Konczak J, Ziegler W, et al. Balance and motor speech impairment in essential tremor. Cerebellum 2009; 8(3): 389-98.

[33] Goldman MS, Kelly PJ. Stereotactic thalamotomy for medically intractable essential tremor. Stereotact Funct Neurosurg 1992; 58(1-4): 22-5.

[34] Krauss JK, Braus DF, Mohadjer M, Nobbe F, Mundinger F. Evaluation of the effect of treatment on movement disorders in astrocytomas of the basal ganglia and the thalamus. J Neurol Neurosurg Psychiatry 1993 ; 56(10): 1113-8.

[35] Louis ED, Faust PL, Vonsattel JP, et al. Neuropathological changes in essential tremor: 33 cases compared with 21 controls. Brain 2007; 130(Pt 12): 3297-307.

[36] Fytagoridis A, Blomstedt P. Complications and Side Effects of Deep Brain Stimulation in the Posterior Subthalamic Area. Stereotact Funct Neurosurg 2010; 88(2): 88-93.

[37] Astrom M, Zrinzo LU, Tisch S, Tripoliti E, Hariz MI, Wardell K. Method for patient-specific finite element modeling and simulation of deep brain stimulation. Med Biol Eng Comput 2009; 47(1): 218 .

[38] Klostermann F, Ehlen F, Vesper J, et al. Effects of subthalamic deep brain stimulation on dysarthrophonia in Parkinson's disease. J Neurol Neurosurg Psychiatry 2008; 79(5): 522-9.

[39] Pinto S, Gentil M, Krack P, et al. Changes induced by levodopa and subthalamic nucleus stimulation on parkinsonian speech. Mov Disord 2005; 20(11): 1507-15. 
[40] Deuschl G, Herzog J, Kleiner-Fisman G, et al. Deep brain stimulation: postoperative issues. Mov Disord 2006; 21 (Suppl 14): S219-37.

[41] Bertrand C, Hardy J, Molina-Negro P, Martínez N. Optimum physiological target for the arrest of tremor. In: Gillingham FJ, Donaldson IML, Eds. Third symposium on Parkinson's diease. Edinburgh: Livingstone, E.S.; 1969. p. 251-9.

[42] Samra K, Riklan M, Levita E, et al. Language and speech correlates of anatomically verified lesions in thalamic surgery for parkinsonism. J Speech Hear Res 1969; 12(3): 510-40.

[43] Selby G. Stereotactic surgery for the relief of Parkinson's disease. 2. An analysis of the results in a series of 303 patients (413 operations). J Neurol Sci 1967; 5(2): 343-75.

[44] Schuurman PR, Bruins J, Merkus MP, Bosch DA, Speelman JD. A comparison of neuropsychological effects of thalamotomy and thalamic stimulation. Neurology 2002; 59(8): 1232-9.

[45] Busenbark KL, Nash J, Nash S, Hubble JP, Koller WC. Is essential tremor benign? Neurology $1991 ; 41(12)$ : 1982-3.

[46] Nguyen HV, Ngian V, Cordato D, Shen Q, Chan DK. Quality of life in a random sample of community dwelling older patients with essential tremor. Acta Neurol Scand 2007; 116(5): 289-92.
[47] Lorenz D, Schwieger D, Moises H, Deuschl G. Quality of life and personality in essential tremor patients. Mov Disord 2006; 21(8): 1114-8.

[48] Ferrara JM, Kenney C, Davidson AL, Shinawi L, Kissel AM, Jankovic J. Efficacy and tolerability of pregabalin in essential tremor: a randomized, double-blind, placebo-controlled, crossover trial. J Neurol Sci 2009 ; 285(1-2): 195-7.

[49] Hariz MI, Hirabayashi H. Is there a relationship between size and site of the stereotactic lesion and symptomatic results of pallidotomy and thalamotomy? Stereotact Funct Neurosurg 1997; 69(1-4 Pt 2): 28-45.

[50] Hariz MI. Correlation between clinical outcome and size and site of the lesion in computed tomography guided thalamotomy and pallidotomy. Stereotact Funct Neurosurg 1990; 54-55: 172-85.

[51] Hirai T, Miyazaki M, Nakajima H, Shibazaki T, Ohye C. The correlation between tremor characteristics and the predicted volume of effective lesions in stereotaxic nucleus ventralis intermedius thalamotomy. Brain 1983; 106: 1001-18.

Received: December 27, 2011

(C) Sandvik et al.; Licensee Bentham Open.

This is an open access article licensed under the terms of the Creative Commons Attribution Non-Commercial License (http://creativecommons.org/licenses/by-nc/3.0/) which permits unrestricted, non-commercial use, distribution and reproduction in any medium, provided the work is properly cited. 